\title{
Homicídios da População de Lésbicas, Gays, Bissexuais, Travestis, Transexuais ou Transgêneros (LGBT) no Brasil: uma Análise Espacial
}

\author{
Homicide of Lesbians, Gays, Bisexuals, Travestis, Transexuals, and \\ Transgender people (LGBT) in Brazil: a Spatial Analysis
}

Wallace Góes Mendes (https://orcid.org/0000-0002-7852-7334) ${ }^{1}$

Cosme Marcelo Furtado Passos da Silva (https://orcid.org/0000-0001-7789-1671) ${ }^{1}$

${ }^{1}$ Programa de PósGraduação em Epidemiologia em Saúde Pública, Escola Nacional de Saúde Pública Sérgio Arouca, Fiocruz. R. Leopoldo Bulhões 1480, Manguinhos. 21041-210 Rio de Janeiro RJ Brasil. wgmendes@uea.edu.br

\begin{abstract}
Violence against LGBT people has always been present in our society. Brazil is the country with the highest number of lethal crimes against LGBT people in the world. The aim of this study was to describe the characteristics of homicides of LGBT people in Brazil using spatial analysis. The LGBT homicide rate was used to facilitate the visualization of the geographical distribution of homicides. Public thoroughfares and the victim's home were the most common places of occurrence. The most commonly used methods for killing male homosexuals and transgender people were cold weapons and firearms, respectively; however, homicides frequently involved beatings, suffocation, and other cruelties. The large majority of victims were aged between 20 and 49 years and typically white or brown. The North, Northeast and Central-West regions, precisely the regions with the lowest HDI,presented LGBT homicide rates above the national rate.LGBT homicides are typically hate crimes and constitute a serious public health problem because they affect young people, particularly transgender people. This problem needs to be addressed by the government, starting with the criminalization of homophobia and the subsequent formulation of public policies to reduce hate crimes and promote respect for diversity. Key words Homicides, LGBT people, Spatial analysis
\end{abstract}

Resumo A violência contra Lésbicas, Gays, Bissexuais, Travestis, Transexuais ou Transgêneros (LGBT) sempre foi presente em nossa sociedade, sendo o Brasil "o país que mais registra crimes letais contra essa população no mundo". O objetivo foi descrever as características dos homicídios de LGBT ocorridos no Brasil por meio de uma análise espacial. Utilizou-se a taxa de homicídios de LGBT para facilitar a visualização da distribuição geográfica dos homicídios. As vias públicas e as residências das vitimas são os lugares mais comuns das ocorrências dos crimes. As armas brancas são as mais usadas no acometimento contra homossexuais masculinos e as armas de fogo para transgêneros, mas ainda é comum os espancamentos, asfixia e outras crueldades com as vitimas. As vítimas estão na faixa etária entre 20 a 49 anos e tendem a ser brancas ou pardas. As regiões Norte, Nordeste e Centro-Oeste apresentaram as taxas de homicídios de LGBT acima da nacional, justamente as regiões com IDH mais baixos. Os homicídios contra LGBT são, em geral, "crimes de ódio" e um grave problema de saúde pública por vitimizar jovens, principalmente os transgêneros. Esses crimes precisam ser enfrentados pelo poder público, que se inicia pela criminalização da homofobia e de elaboração de políticas públicas que diminuam a cultura do ódio e disseminem o respeito à diversidade.

Palavras-chave Homicídios, População LGBT, Análise espacial 


\section{Introdução}

Dentre as mortes por causas externas, as provocadas por violência e agressões intencionais têm aumentado no Brasil, fazendo com que hoje o país tenha o maior número absoluto de homicídios do mundo ${ }^{1,2}$, o que pode ser encarado como um grave problema de saúde pública ${ }^{3,4}$. Esse tipo de violência pode ser compreendido como um fenômeno complexo, que causa grande impacto na expectativa de vida das populações, pois geralmente atinge os jovens, negros e pessoas de baixa renda de países em desenvolvimento ${ }^{5-7}$.

De acordo com o relatório "World Statistics 2019”, publicado pela Organização Mundial da Saúde (OMS), estima-se que no ano de 2016 houve 477.000 homicídios em todo o mundo ${ }^{8}$, sendo que o Brasil apresentou cerca de $12,8 \%{ }^{9}$ do total mundial, o que representa a sétima maior taxa de homicídio do continente americano ${ }^{8}$.

O Atlas da Violência brasileiro de 2019 registrou 65.602 homicídios para dados do ano de 2017 , o que aponta uma taxa de 31,6 por $100 \mathrm{mil}$ habitantes. Das vítimas, 54,5\% eram jovens entre 15 a 29 anos, 91,8\% das vítimas eram homens, $77,0 \%$ foram mortos por armas de fogo; $75,5 \%$ eram negras e residiam, em geral, nas regiões Norte e Nordeste ${ }^{9}$.

A Transgender Europe (TGEU) relatou a existência de 2.609 homicídios informados de transgêneros em 71 países no período de 2008 a 2017, tendo o Brasil o maior número de registros ${ }^{10}$.

No Atlas da Violência de 2019 há uma seção inédita que aborda a questão da violência contra a população Lésbicas, Gays, Bissexuais, Travestis, Transexuais ou Transgêneros (LGBT) no Brasil de 2011 a 2017, estando dividida em dados do Disque 100 e do Sistema de Informação de Agravos de Notificação (SINAN). No Disque 100 foram registradas 1.720 denúncias de violações de direitos humanos dos LGBT, destas 193 foram de homicídios, 23 de tentativas e 423 de lesão corporal no ano de 2017. No SINAN, no ano de 2016, o número de casos de violência contra homossexuais/bissexuais foi de cerca de 6.800, salientando que mais da metade das denúncias foram por causa da violência física, porém ainda há registros de violência psicológica e tortura ${ }^{9}$.

Segundo o Grupo Gay da Bahia (GGB), o Brasil "é o país com a maior quantidade de registros de crimes letais contra LGBT do mundo", seguido pelo México e Estados Unidos ${ }^{11-13}$. Em 2018, o GGB registrou que 420 LGBT tiveram mortes violentas no Brasil, ou seja, a cada 20 horas é assassinado um indivíduo $\mathrm{LGBT}^{12}$.
O estudo tem a finalidade de apresentar as características dos homicídios de LGBT ocorridos no Brasil no período de 2002 a 2016, por meio de uma análise espacial, logo o estudo não tem o intuito de discussões sociopolíticas acerca da homofobia. Dessa forma, se condicionará em analisar os homicídios contra LGBT ocorridos no Brasil e registrados pelo GGB, que necessariamente não ocorreram por motivações homofóbicas, pois é algo difícil de comprovar por falta de informações desses crimes.

\section{Materiais e métodos}

Como os dados oficiais sobre homicídios de LGBT publicados recentemente no Brasil pelo Atlas da Violência são subnotificados, logo fez-se necessário pensar numa alternativa viável para a realização de um estudo que retratasse esse crime ${ }^{9}$. A alternativa mais factível foi utilizar os dados do GGB, que é uma Organização Não Governamental (ONG) e que desde 1980 tem registrado os homicídios e suicídios de LGBT, inclusive aqueles com possíveis motivações homofóbicas ${ }^{12-14}$. Vale salientar que instituições internacionais como a TGEU, a International Lesbian, Gay, Bisexual, Trans and Intersex Association (ILGA), a Organização das Nações Unidas (ONU) e a imprensa brasileira utilizam os dados dos relatórios do GGB em suas webpages ${ }^{10,15,16}$.

O Ministério dos Direitos Humanos brasileiro formulou um relatório no final de 2018, que ratifica os dados do GGB e ainda estimou que 8.027 indivíduos LGBT foram assassinados no país entre 1963 e 2018, em razão de orientação sexual ou identidade de gênero ${ }^{17}$. O GGB documentou mais de 5 mil assassinatos de indivíduos LGBT até 2018, dados que são baseados em notícias publicadas na imprensa, pesquisa na internet e informações enviadas pelos próprios militantes LGBT, sendo estas as formas de obtenção das informações ${ }^{12}$.

Para minimizar a subnotificação dos registros, os homicídios documentados no período de estudo foram revisados com buscas exaustivas na internet com ajuda de um técnico do GGB, o que resultou em correções, alterações e ainda complementações de algumas informações. Uma estimativa conservadora indica que para cada homicídio de LGBT registrado e noticiado existem dois outros que não foram notificados ${ }^{18}$, porém acredita-se que no Brasil esse número possa ser ainda maior ${ }^{19}$.

O indicador "taxa de homicídio de LGBT" foi a principal variável de interesse do estudo, o que 
é comum numa análise espacial. Foram calculadas as taxas de homicídios para localidades com mais de 100 mil habitantes a partir de 2002, ano inicial do estudo, todavia não foi calculada a taxa padronizada por falta de informações nos dados disponíveis.

Como não há informações sobre a taxa de homicídios de LGBT no Brasil, fez-se necessário a escolha de um parâmetro para realizar comparações. A estatística quartil foi escolhida para os Estados e o Índice de Desenvolvimento Humano (IDH) para as capitais e demais municípios, sendo este o indicador social mais usado no mundo $^{20}$. Dessa forma, foi possível a comparação das taxas de homicídios entre os municípios e estados brasileiros.

Uma condição indiscutível nos dados registrados do GGB é a subnotificação, pois os mesmos não são provenientes de informações oficiais do governo. Então, uma tentativa de minimizar esse viés foi agrupar os casos por quinquênio, assim, para calcular as taxas de homicídios por 100 mil habitantes foi necessário dividir o período de 15 anos em três períodos de cinco (2002 a 2006, 2007 a 2011 e 2012 a 2016), no intuito de tornar os resultados mais robustos, comparativos, representativos e de melhor visualização espacial. Deste modo, as taxas de homicídios de LGBT foram calculadas com base no somatório de cada quinquênio (numerador da fração) dividido por $10 \%$ da população brasileira (denominador) nos anos centrais dos períodos de 5 anos (2004, 2009 e 2014). Vale destacar que $10 \%$ é uma estimativa conservadora da quantidade de LGBT residentes no Brasil, porque ainda não existe pesquisa que estime essa representatividade ${ }^{21-23}$.

Alguns estudos de outros países também estimam que a população LGBT representa, em média, $10 \%$ de suas populações. Uma pesquisa da Universidade da Califórnia (UCLA) no ano de 2006 nas 13 maiores cidades dos Estados Unidos, concluiu que $8,1 \%$ da população se declararam ser $\mathrm{LGBT}^{24}$. Na Holanda, 10\% dos homens e $11 \%$ das mulheres relataram sentir atração sexual por alguém do mesmo sexo, conforme o estudo do instituto Rutgers Nisso Groep, realizado em $2009^{25}$. $\mathrm{O}$ estudo da empresa de pesquisa de mercado YouGov chegou à estimativa de que $11 \%$ da população da Inglaterra são $\mathrm{LGBT}^{26}$. Na Itália, cerca de $6,7 \%$ da população declarou que tiveram relações sexuais com uma pessoa do mesmo sexo, de acordo com o estudo do Istituto Nazionale di Statistica ${ }^{27}$.

Para a visualização das taxas de homicídios foi utilizada a análise espacial por meio das téc- nicas de Cliff et al. ${ }^{28}$, em que se construiu mapas por áreas utilizando os quartis, pois não existe uma divisão de classes pré-estabelecidas para taxas de homicídios ${ }^{29}$. No cálculo das taxas e na elaboração dos mapas foram utilizados os softwares R 3.5.3 e QGIS 3.4.5.

A medida de dependência espacial utilizada foi o coeficiente $I$ de Moran $^{30}$, que foi aplicada para avaliar a hipótese de autocorrelação espacial entre as taxas de homicídios de LGBT nos três períodos, usando 5\% de nível de significância ${ }^{31}$. Alguns trabalhos $^{32,33}$ ressaltam a necessidade de realizar um teste de hipótese, no qual a hipótese nula $\left(H_{0}\right)$ indica que as observações foram geradas por uma distribuição sem dependência espacial. Sendo assim, a rejeição de $H_{0}$ acrescida de um valor positivo ou negativo (próximos de 1) do coeficiente indicaria a dependência das localidades. Após testes de diferentes matrizes, a matriz de proximidade espacial adotada utilizou a distância entre os centroides dos Estados maior que 2.500 quilômetros, pois essa configuração foi a mais significativa ( $p$ valor $\leq 0,05)$ para os testes de hipóteses.

Foram elaborados mapas de Kernel para as taxas de homicídios, onde se analisou geograficamente o comportamento de padrões nas regiões brasileiras. O mapa foi plotado por meio métodos de interpolação, apresentando a intensidade pontual do fenômeno em toda a região de estudo por quilômetros quadrados detalhados na escala 1:2000. Portanto, se teve uma visão geral da intensidade da taxa de homicídios de LGBT em todas as regiões do mapa brasileiro ${ }^{34}$.

Por fim, neste estudo epidemiológico, ecológico e descritivo optou-se por analisar o recorte temporal de 2002 a 2016, pois foram os dados mais atuais disponíveis no início do estudo, com o intuito de obter os resultados mais fidedignos ou as estimativas mais próximas da realidade.

\section{Resultados}

De acordo com os registros do GGB, no período de 2002 a 2016 houve 3.100 homicídios contra LGBT no Brasil, detalhados na Tabela 1. Para o melhor entendimento dos resultados, as identidades de gênero ou orientações sexuais foram separadas em três grupos: Homossexuais, Transgêneros e Outras. Aproximadamente 59,3\% eram Homossexuais, que também inclui os Bissexuais; 35,6\% eram Transgêneros, que também inclui os Intersexuais, "Transexuais", "Cross-dressers" e "Travestis"; e 5,1\% foram classificados como Outras, que inclui as Lésbicas, os Heterossexuais re- 
Tabela 1. Estatísticas descritivas dos crimes, vítimas e autores dos homicídios de LGBT no Brasil, 2002-2016.

\begin{tabular}{|c|c|c|c|c|c|c|c|c|c|}
\hline & \multirow{4}{*}{ Variáveis } & \multicolumn{8}{|c|}{ Homicídios } \\
\hline & & \multicolumn{8}{|c|}{ Identidades de Gênero/Orientações Sexuais } \\
\hline & & \multicolumn{2}{|c|}{ Homossexuais } & \multicolumn{2}{|c|}{ Transgêneros } & \multicolumn{2}{|c|}{ Outras ${ }^{\star}$} & \multicolumn{2}{|c|}{ Total } \\
\hline & & $\mathbf{N}$ & $\%$ & $\mathbf{N}$ & $\%$ & $\mathbf{N}$ & $\%$ & $\mathbf{N}$ & $\%$ \\
\hline \multirow{3}{*}{$\begin{array}{l}\text { "Divisão } \\
\text { geográfica" }\end{array}$} & Capital & 891 & 48,5 & 522 & 47,2 & 73 & 46,5 & 1486 & 47,9 \\
\hline & Interior & 947 & 51,5 & 583 & 52,8 & 84 & 53,5 & 1614 & 52,1 \\
\hline & Total & 1838 & 100,0 & 1105 & 100,0 & 157 & 100,0 & 3100 & 100,0 \\
\hline \multirow{5}{*}{$\begin{array}{l}\text { "Local da } \\
\text { ocorrência " }\end{array}$} & Residência & 791 & 47,5 & 170 & 17,3 & 49 & 33,6 & 1010 & 36,1 \\
\hline & Via Pública & 740 & 44,4 & 756 & 76,8 & 77 & 52,7 & 1573 & 56,2 \\
\hline & Estabelecimento privado & 128 & 7,7 & 58 & 5,9 & 20 & 13,7 & 206 & 7,4 \\
\hline & Estabelecimento público & 8 & 0,5 & - & - & - & - & 8 & 0,3 \\
\hline & $\begin{array}{ll}\text { Total }\end{array}$ & 1667 & 100,0 & 984 & 100,0 & 146 & 100,0 & 2797 & 100,0 \\
\hline \multirow{6}{*}{$\begin{array}{l}\text { "Tipo de armas } \\
\text { ou Formas de } \\
\text { acomentimento" }\end{array}$} & Arma branca & 626 & 36,0 & 241 & 23,6 & 58 & 38,2 & 925 & 31,7 \\
\hline & Arma de fogo & 431 & 24,8 & 509 & 49,8 & 63 & 41,4 & 1003 & 34,4 \\
\hline & Espancamento & 327 & 18,8 & 147 & 14,4 & 20 & 13,2 & 494 & 16,9 \\
\hline & Asfixia & 243 & 14,0 & 66 & 6,5 & 6 & 3,9 & 315 & 10,8 \\
\hline & Outras ${ }^{\star *}$ & 114 & 6,5 & 59 & 5,8 & 5 & 3,3 & 178 & 6,1 \\
\hline & Total & 1741 & 100,0 & 1022 & 100,0 & 152 & 100,0 & 2915 & 100,0 \\
\hline \multirow{5}{*}{$\begin{array}{l}\text { "Quantidade de } \\
\text { golpes ou tiros" }\end{array}$} & 1 & 22 & 7,4 & 21 & 10,2 & 6 & 15,8 & 49 & 9,1 \\
\hline & 2 a 5 & 146 & 49,2 & 117 & 57,1 & 23 & 60,5 & 286 & 53,0 \\
\hline & 6 a 10 & 52 & 17,5 & 32 & 15,6 & 6 & 15,8 & 90 & 16,7 \\
\hline & $>10$ & 77 & 25,9 & 35 & 17,1 & 3 & 7,9 & 115 & 21,3 \\
\hline & Total & 297 & 100,0 & 205 & 100,0 & 38 & 100,0 & 540 & 100,0 \\
\hline \multirow{8}{*}{$\begin{array}{l}\text { "Faixa etária da } \\
\text { Vítima (em anos)" }\end{array}$} & $<15$ & 12 & 0,8 & 8 & 1,1 & 2 & 1,4 & 22 & 0,9 \\
\hline & 15 a 19 & 105 & 6,6 & 97 & 13,0 & 22 & 15,7 & 224 & 9,1 \\
\hline & 20 a 29 & 382 & 24,2 & 369 & 49,5 & 58 & 41,4 & 809 & 32,8 \\
\hline & 30 a 39 & 414 & 26,2 & 200 & 26,8 & 34 & 24,3 & 648 & 26,3 \\
\hline & 40 a 49 & 372 & 23,6 & 66 & 8,8 & 14 & 10,0 & 452 & 18,3 \\
\hline & 50 a 59 & 184 & 11,7 & 4 & 0,5 & 8 & 5,7 & 196 & 8,0 \\
\hline & $>59$ & 110 & 7,0 & 2 & 0,3 & 2 & 1,4 & 114 & 4,6 \\
\hline & Total & 1579 & 100,0 & 746 & 100,0 & 140 & 100,0 & 2465 & 100,0 \\
\hline \multirow{3}{*}{$\begin{array}{l}\text { Raça/cor da pele } \\
\text { da Vítima }\end{array}$} & Branca & 297 & 51,7 & 202 & 54,6 & 29 & 50,9 & 528 & 52,7 \\
\hline & Parda & 235 & 40,9 & 138 & 37,3 & 23 & 40,4 & 396 & 39,6 \\
\hline & Preta & 42 & 7,3 & 30 & 8,1 & 5 & 8,8 & 77 & 7,7 \\
\hline Total & & 574 & 100,0 & 370 & 100,0 & 57 & 100,0 & 1001 & 100,0 \\
\hline \multirow[t]{9}{*}{$\begin{array}{l}\text { Profissão da } \\
\text { Vítima }\end{array}$} & $\begin{array}{l}\text { Profissionais de nível superior, } \\
\text { professores ou empresários }\end{array}$ & 477 & 44,4 & 16 & 3,6 & 14 & 31,8 & 507 & 32,4 \\
\hline & Serviços gerais e autônomos & 336 & 31,3 & 62 & 14,0 & 16 & 36,4 & 414 & 26,5 \\
\hline & Profissional do sexo & 22 & 2,0 & 353 & 79,5 & - & - & 375 & 24,0 \\
\hline & $\begin{array}{l}\text { Estudantes, aposentados ou } \\
\text { desempregados }\end{array}$ & 111 & 10,3 & 5 & 1,1 & 11 & 25,0 & 127 & 8,1 \\
\hline & Sacerdotes e religiosos & 65 & 6,0 & 3 & 0,7 & - & - & 68 & 4,4 \\
\hline & Profissionais de nível médio & 46 & 4,3 & 3 & 0,7 & - & - & 49 & 3,1 \\
\hline & Militares & 15 & 1,4 & - & - & 3 & 6,8 & 18 & 1,2 \\
\hline & Militantes LGBT & 3 & 0,3 & 2 & 0,5 & - & - & 5 & 0,3 \\
\hline & Total & 1075 & 100,0 & 444 & 100,0 & 44 & 100,0 & 1563 & 100,0 \\
\hline
\end{tabular}

conhecidos erroneamente como Homossexuais e os "T-lovers", que são amantes/admiradores de Transgêneros e "Travestis".
No que se refere aos homicídios de homossexuais, os crimes distribuíram-se nos municípios do interior (não capital), porém podem fazem 
Tabela 1. Estatísticas descritivas dos crimes, vítimas e autores dos homicídios de LGBT no Brasil, 2002-2016.

\begin{tabular}{|c|c|c|c|c|c|c|c|c|c|}
\hline & \multirow{4}{*}{ Variáveis } & \multicolumn{8}{|c|}{ Homicídios } \\
\hline & & \multicolumn{8}{|c|}{ Identidades de Gênero/Orientações Sexuais } \\
\hline & & \multicolumn{2}{|c|}{ Homossexuais } & \multicolumn{2}{|c|}{ Transgêneros } & \multicolumn{2}{|c|}{ Outras ${ }^{\star}$} & \multicolumn{2}{|c|}{ Total } \\
\hline & & $\mathbf{N}$ & $\%$ & $\mathbf{N}$ & $\%$ & $\mathbf{N}$ & $\%$ & $\mathbf{N}$ & $\%$ \\
\hline "Faixa etária do & $<15$ & 4 & 1,2 & - & - & 2 & 1,4 & 6 & 1,1 \\
\hline Autor (em anos)" & 15 a 19 & 118 & 35,2 & 18 & 21,2 & 22 & 15,7 & 158 & 28,2 \\
\hline & 20 a 29 & 158 & 47,2 & 43 & 50,6 & 58 & 41,4 & 259 & 46,3 \\
\hline & 30 a 39 & 38 & 11,3 & 8 & 9,4 & 34 & 24,3 & 80 & 14,3 \\
\hline & 40 a 49 & 14 & 4,2 & 11 & 12,9 & 14 & 10,0 & 39 & 7,0 \\
\hline & 50 a 59 & 1 & 0,3 & 4 & 4,7 & 8 & 5,7 & 13 & 2,3 \\
\hline & $>59$ & 2 & 0,6 & 1 & 1,2 & 2 & 1,4 & 5 & 0,9 \\
\hline & Total & 335 & 100,0 & 85 & 100,0 & 140 & 100,0 & 560 & 100,0 \\
\hline \multirow{6}{*}{$\begin{array}{l}\text { Profissão do } \\
\text { Autor }\end{array}$} & Profissionais do Sexo & 36 & 48,6 & 6 & 26,1 & 3 & 50,0 & 45 & 43,7 \\
\hline & Militares & 13 & 17,6 & 16 & 69,6 & 2 & 33,3 & 31 & 30,1 \\
\hline & $\begin{array}{l}\text { Estudantes, aposentados ou } \\
\text { desempregados }\end{array}$ & 12 & 16,2 & - & - & 1 & 16,7 & 13 & 12,6 \\
\hline & $\begin{array}{l}\text { Profissionais de Nível } \\
\text { Superior }\end{array}$ & 7 & 9,5 & - & - & - & - & 7 & 6,8 \\
\hline & $\begin{array}{l}\text { Serviços Gerais e } \\
\text { Autônomos }\end{array}$ & 6 & 8,1 & 1 & 4,3 & - & - & 7 & 6,8 \\
\hline & Total & 74 & 100,0 & 23 & 100,0 & 6 & 100,0 & 103 & 100,0 \\
\hline
\end{tabular}

Nota: * Inclui as lésbicas, os heterossexuais reconhecidos erroneamente como homossexuais e os “t-lovers”, que são amantes/ admiradores de transgêneros e "travestis". ** Na categoria “Outras” estão incluídos pauladas, apedrejamento, decapitação, atropelamento, empalamento, afogamento, envenenamento e tortura.

fazer parte das áreas metropolitanas $(51,5 \%)$; em suas residências $(47,5 \%)$; por arma branca $(36,0 \%)$ e com 2 a 5 golpes $(49,2 \%)$. As vítimas estavam entre 30 e 39 anos (26,2\%); de raça/cor branca $(51,7 \%)$ e eram profissionais de nível superior, professores ou empresários $(44,4 \%)$. Dentre os autores identificados, aproximadamente a metade estava entre 20 e 29 anos (47,2\%) e 48,6\% eram profissionais do sexo.

Em relação aos homicídios de transgêneros, os crimes distribuíram-se nos municípios do interior (não capital), porém podem fazem fazer parte das áreas metropolitanas $(52,8 \%)$, em vias públicas $(76,8 \%)$; por arma de fogo $(49,8 \%)$ e com 2 a 5 golpes ou tiros $(57,1 \%)$. As vítimas tinham de 20 a 29 anos (49,5\%); de raça/cor branca $(54,6 \%)$ e eram profissionais do sexo $(79,5 \%)$. Dentre os autores identificados, aproximadamente a metade tinha entre 20 a 29 anos $(50,6 \%)$ e cerca de dois terços eram militares $(69,6 \%)$.

No geral, os crimes distribuíram-se no interior $(52,1 \%)$; em vias públicas $(56,2 \%)$; por arma de fogo $(34,4 \%)$ e com 2 a 5 golpes/tiros $(53,0 \%)$. As vítimas tinham de 20 a 29 anos (32,8\%); de raça/cor branca $(52,7 \%)$ e eram profissionais de nível superior, professores ou empresários
(32,4\%). Dentre os autores identificados, aproximadamente a metade tinha entre 20 a 29 anos $(46,3 \%)$ e cerca da metade eram profissionais do sexo $(43,7 \%)$.

Vale salientar que existem poucas informações acerca dos autores, principalmente pela existência da subnotificação desses crimes. Isso ocorre pela ineficiência do sistema de justiça criminal brasileiro, gerando o não enfrentamento da homofobia ${ }^{12,13}$.

\section{Estados (Unidades da Federação)}

No período de 2002 a 2006 houve 7 estados que apresentaram taxas de homicídios acima do $3^{\circ}$ quartil $(4,36)$, que foram Amazonas, Mato Grosso do Sul, Goiás, Rio Grande do Norte, Paraíba e Pernambuco. No período de 2007 a 2011 houve 6 estados com taxas de homicídios acima do $3^{\circ}$ quartil $(8,60)$, que foram Rondônia, Mato Grosso do Sul, Paraíba, Pernambuco, Alagoas e Sergipe. No período de 2012 a 2016 houve 6 estados com taxas de homicídios acima do $3^{\circ}$ quartil $(14,26)$, que foram Amazonas, Rondônia, Mato Grosso do Sul, Paraíba, Alagoas e Sergipe, como é visto na Figura 1. 

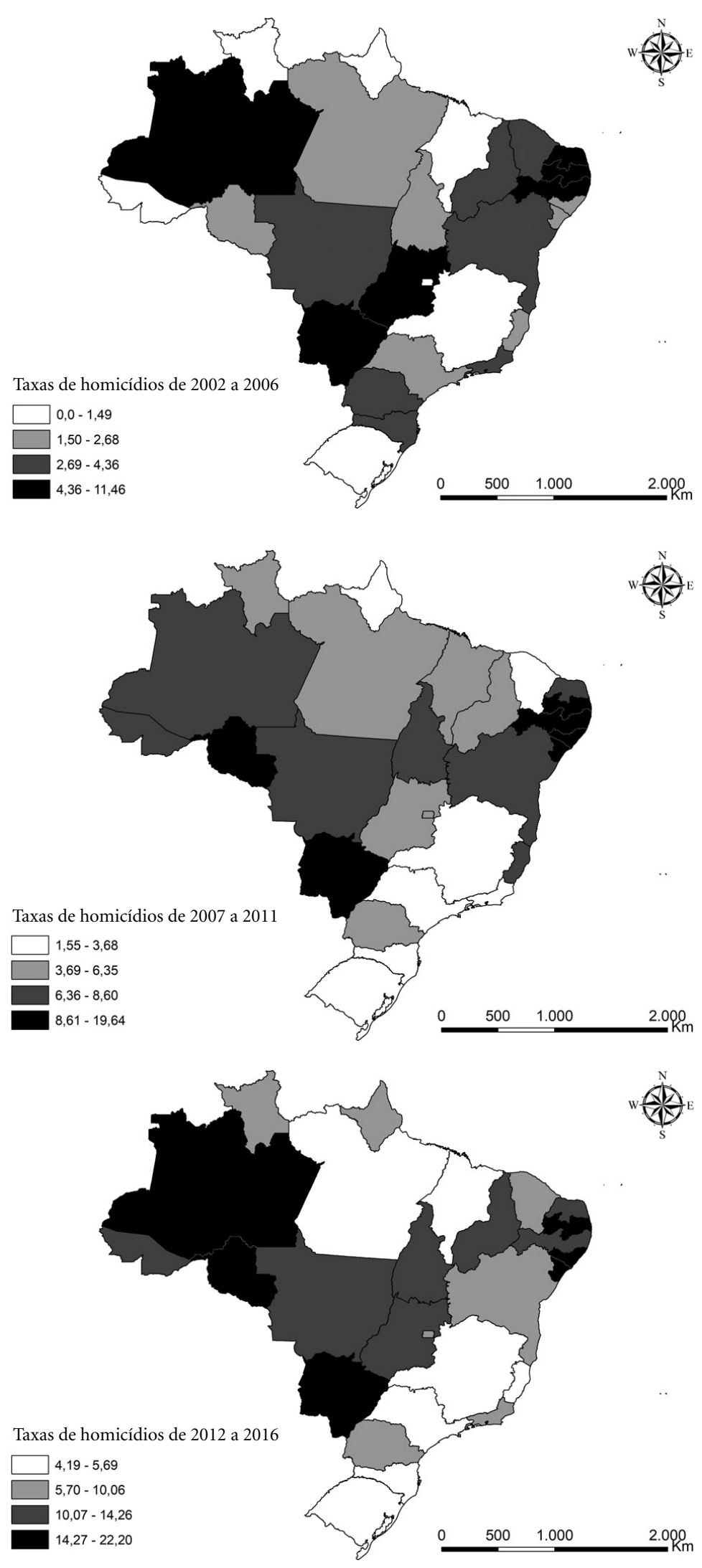

Figura 1. Evolução espacial das taxas de homicídios por Estados brasileiros de 2002 a 2016. 
Os estados da Paraíba e Mato Grosso do Sul apresentaram taxas de homicídios acima do $3^{\circ}$ quartil nos três períodos; os estados do Amazonas, Rondônia, Pernambuco, Alagoas e Sergipe apresentaram em dois períodos, enquanto os estados do Rio Grande do Norte e Goiás apresentaram suas taxas de homicídios acima do $3^{\circ}$ quartil apenas em um período.

\section{Cidades}

O crescimento de homicídios contra LGBT no Brasil fica evidente quando se observa a evolução espacial das taxas de homicídios por municípios brasileiros no período de 2002 a 2016 . No período de 2002 a 2006, apenas 158 cidades registraram este tipo específico de homicídio, o que representa $2,84 \%$ do total de cidades. No período de 2006 a 2011, o número de cidades que registraram homicídios deste tipo foi de 310, o que representa $5,57 \%$ das cidades. No período de 2011 a 2016, já eram 558 cidades que registraram os homicídios contra LGBT, o que representa $10,02 \%$ do total de cidades brasileiras.

\section{Capitais}

Utilizando a cidade de Florianópolis como parâmetro para as capitais, porque tem o maior IDH entre as capitais ${ }^{35}$, há 15 capitais que apresentaram as taxas de homicídios para o período (2002 a 2016) acima da taxa de Florianópolis, que registrou uma taxa média de 12,09 homicídios por 100 mil habitantes. As 15 capitais com situações mais críticas apresentaram suas taxas de homicídios médias acima de 12 homicídios por 100 mil habitantes foram: João Pessoa $(44,25)$; Palmas (31,51); Recife (27,03); Manaus $(24,39)$; Porto Velho (24,07); Cuiabá $(23,76)$; Maceió (23,33); Natal $(23,28)$; Teresina $(22,04)$; Goiânia (20,22); Aracaju (17,26); Vitória (16,39); Campo Grande $(16,21)$; Salvador $(15,65)$ e Curitiba $(12,70)$, conforme é visto na Figura 2.

Comparando as variações do período de 2002 a 2006 para 2007 a 2011, as capitais com maiores variações positivas foram: Maceió (797,25\%); Aracajú $(442,50 \%)$ e Brasília $(337,70)$. As maiores variações negativas foram: Florianópolis $(-59,37 \%)$; Goiânia $(-52,43 \%)$ e Manaus $(-45,04 \%)$. Do período de 2007 a 2011 para 2012 a 2016, as capitais com maiores variações positivas foram Porto Alegre (241,36\%); Manaus $(223,74 \%)$ e São Paulo (156,26\%). As maiores variações negativas foram: Vitória $(-59,59 \%)$; Maceió (-38,73\%) e São Luís (-35,13\%).

\section{Municípios (não capital)}

$\mathrm{Na}$ análise das cidades que não são capitais foi escolhido o município de Pouso Alegre, Estado de Minas Gerais, como parâmetro, pois apresentou o maior IDH entre 26 cidades que apresentaram casos significativos ${ }^{35}$. Destas, há 18 municípios que apresentaram as taxas médias de homicídios para o período (2002 a 2016) acima de Pouso Alegre, que registrou uma taxa média de 12,51 homicídios por 100 mil habitantes. Os 18 municípios com situações mais críticas apresentaram suas taxas médias de homicídios acima de 12 homicídios por 100 mil habitantes foram: Caruaru - PE (23,3); Uberaba - MG $(21,0)$; Itabuna - BA (20,5); Simões Filho - BA (20,3); Rondonópolis - MT (19,3); Cabo de Santo Agostinho - PE (17,6); Várzea Grande - MT (16,8); Paulo Afonso - BA (15,6); Olinda - PE $(15,4)$; Vitória de Santo Antão - PE (15,2); Lauro de Freitas BA(14,1); Teixeira de Freitas - BA $(13,9)$; Camaragibe - PE (13,7); Araguaína - TO (13,5); Arapiraca - AL (13,5); Camaçari - BA $(13,2)$; Feira de Santana - BA $(13,1)$ e Porto Seguro - BA $(12,8)$.

Comparando as variações do período de 2002 a 2006 com o de 2007 a 2011, os municípios com maiores variações positivas foram: Simões Filho - BA (440,62\%); Uberaba - MG (364,10\%) e Camaragibe - PE (201,09\%). As maiores variações negativas foram: Jaboatão dos Guararapes - PE $(-8,39 \%)$; Dourados - MS (-5,24\%) e Paulo Afonso - BA $(-4,81 \%)$. Do período de 2007 a 2011 para 2012 a 2016, os municípios com maiores variações positivas foram Dourados - MG (351,35\%); Várzea Grande - MT (306,42\%) e Nova Iguaçu - RJ (145,27). As maiores variações negativas foram: Simões Filho - BA (-100,00\%); Olinda - PE $(-65,94 \%)$ e Paulo Afonso - BA (-54,91\%).

\section{Dependência espacial}

Inicialmente, tentou-se aplicar o $I$ de Moran para os municípios como as possíveis áreas de análise, porém como aproximadamente $90 \%$ dos municípios apresentaram taxas de homicídios iguais a zero, logo foi necessário o agrupamento das áreas por estados como forma de satisfazer os pressupostos do uso do coeficiente. Deste modo, mesmo não sendo usual o agrupamento por Estados, foi aplicado o $I$ de Moran em três períodos de 5 anos (2002 a 2006; 2007 a 2011 e 2012 a 2016). Vale ressaltar, que o período de 2002 a 2006 houve três estados que apresentaram as taxas de homicídios iguais a zero, então foi necessário o descarte para a aplicação do coeficiente. 

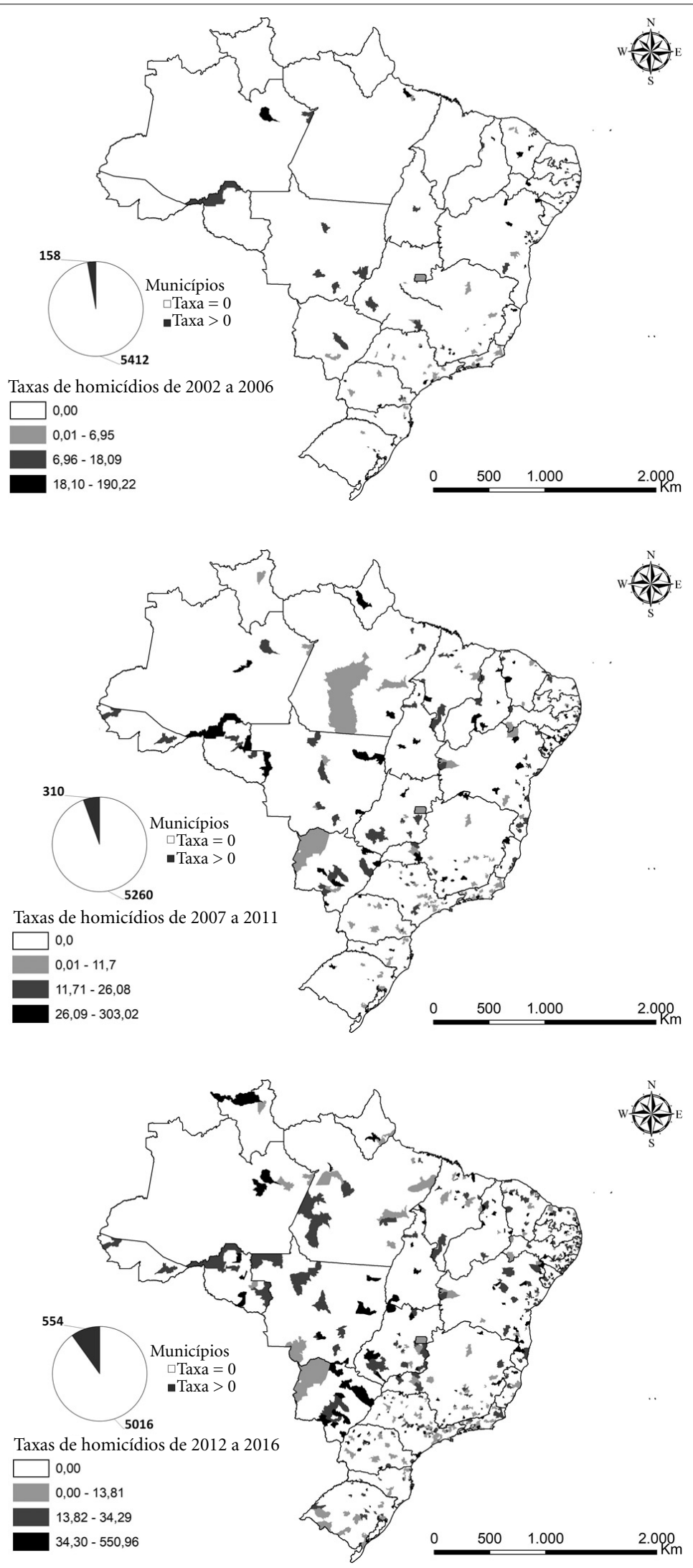

Figura 2. Evolução espacial das taxas de homicídios por municípios brasileiros de 2002 a 2016. 
Uma vez que o I de Moran foi significativo para os três períodos, então se descartou a hipótese nula $(\mathrm{Ho})$ de ausência de autocorrelação espacial entre os estados. Sendo assim, há evidências, ao nível de $5 \%$ de significância, que existe autocorrelação espacial positiva entre as taxas de homicídios dos três períodos para os estados. Concluindo-se que não há como afirmar que os homicídios contra LGBT ocorreram de forma independente entre os estados. Logo, não se pode interpretar os resultados encontrados de forma isolada como se esses homicídios fossem um fenômeno social particular de cada estado.

Para se ter uma visão geral da intensidade do processo de crescimento das taxas de homicídios em todas as regiões do Brasil, foram construídos mapas de Kernel para os três períodos de análise, utilizando quatros classes, que foram divididas pelos quartis. Sendo assim, quanto mais escuro o mapa as taxas são maiores, logo é observado que as localidades onde se concentram as regiões metropolitanas são as que possuem maiores taxas de homicídios contra LGBT no Brasil, como é visto na Figura 3.

\section{Discussão}

Este trabalho é pioneiro no sentido de apresentar informações mais robustas acerca de homicídios contra LGBT no Brasil. A cada ano o quantitativo de homicídios tem crescido no país pela ausência de políticas públicas no sentido de combater essa violência ${ }^{12,14}$. Só a criminalização da homofobia não dará solução a questão, porém a lei federal aprovada recentemente já é um começo na busca da diminuição dos casos de violência contra essa populaçãa ${ }^{11,13,18}$. Portanto, ao trazer informações dos homicídios sobre a população LGBT no Brasil de 2002 a 2016, o estudo traz à luz uma realidade pouco conhecida ou até mesmo ignorada pelo poder público.

Dentre os principais resultados do estudo, observou-se que a taxa de homicídios foi semelhante entre as capitais e os municípios do interior (não capital), algo não descrito em outros estudos; há o predomínio da mortalidade da população LGBT por homicídio em vias públicas $^{14,18,36-42}$ e nas residências das vítimas ${ }^{14,18,36-44}$. As armas de fogo, as armas brancas, espancamentos e asfixias são as formas mais frequentes de acometimentos ${ }^{14,18,36-41,43,45-47}$. Os crimes tendem a ter mais de um golpe ou tiro nas vítimas assassinadas, o que sugere ser um "crime de ódio"14,41,43,44,47 .

No que se refere às vítimas, os homossexuais masculinos e os transgêneros são os mais acome- tidos $^{38,43}$. A faixa etária entre 20 e 49 anos é a mais comum $^{12,36,38-40,46}$, ressaltando que os transgêneros, em geral, são mais novos ${ }^{45,48}$. As vítimas tendem a ser de raça/cor branca ${ }^{12,37,41,43-45,48}$ ou parda ${ }^{43,45,48}$, sendo que a maioria eram profissionais de nível superior, professores ou empresários ${ }^{12,36,38,40}$. Os autores identificados possuem a faixa etária abaixo de 30 anos $^{37,40-44,47}$, em geral, são profissionais do $\operatorname{sexo}^{36,38}$, militares e estudantes ${ }^{36-40}$.

$\mathrm{Na}$ análise espacial foram perceptíveis que os estados que possuem taxas de homicídios acima do $3^{\circ}$ quartil estão localizados nas regióes Norte, Nordeste e Centro-Oeste ${ }^{1,49,50}$. Quando comparase com as taxas de homicídios para a população geral no período de 2006 a 2016 observa-se o mesmo padrão, com exceção do estado de Pernambuco que diminuiu (-10,2\%) e Rio Grande do Sul que aumentou suas taxas $(58,0 \%)$, neste período ${ }^{1}$.

Para as capitais, onde se utilizou-se a cidade de Florianópolis como parâmetro, há 15 capitais que apresentaram as taxas de homicídios para os três períodos acima desta, que foram: João Pessoa, Palmas, Recife, Manaus, Porto Velho, Cuiabá, Maceió, Natal, Teresina, Goiânia, Aracaju, Vitória, Campo Grande, Salvador e Curitiba ${ }^{1,49}$. Quando se compara ao ranking das cidades mais violentas do mundo, oito das 15 capitais estão nessa lista, que são João Pessoa, Recife, Manaus, Maceió, Natal, Teresina, Aracaju e Salvador ${ }^{51}$. As capitais de Fortaleza, Belém e Macapá também aparecem nesse ranking, mas não estão entre as 15 capitais mais violentas para LGBT.

Para os municípios (não capitais), que foi escolhido o município de Pouso Alegre - MG como parâmetro, houve 18 municípios que apresentaram as taxas de homicídio médias para os três períodos acima de Pouso Alegre ${ }^{1,49}$. Quando se compara ao ranking das cidades mais violentas do mundo, apenas a cidade de Feira de Santana BA aparece em ambas as listas ${ }^{51}$.

O I de Moran verificou-se a presença de autocorrelação espacial positiva entre as taxas de homicídios dos três períodos para os estados, o que significa que os resultados não podem ser interpretados de forma isolada, pois fazem parte de um mesmo fenômeno sociopolítico e de um grave problema de saúde pública. Na construção de mapas de Kernel para verificação da intensidade das taxas de homicídios contra LGBT, observouse que as maiores taxas de homicídios se concentram nas regiões metropolitanas. Na população geral ocorre o mesmo fenômeno, pois as taxas de homicídios também são maiores nas regiões metropolitanas, algo constatado no Atlas da Violência $2019^{9,52}$. 

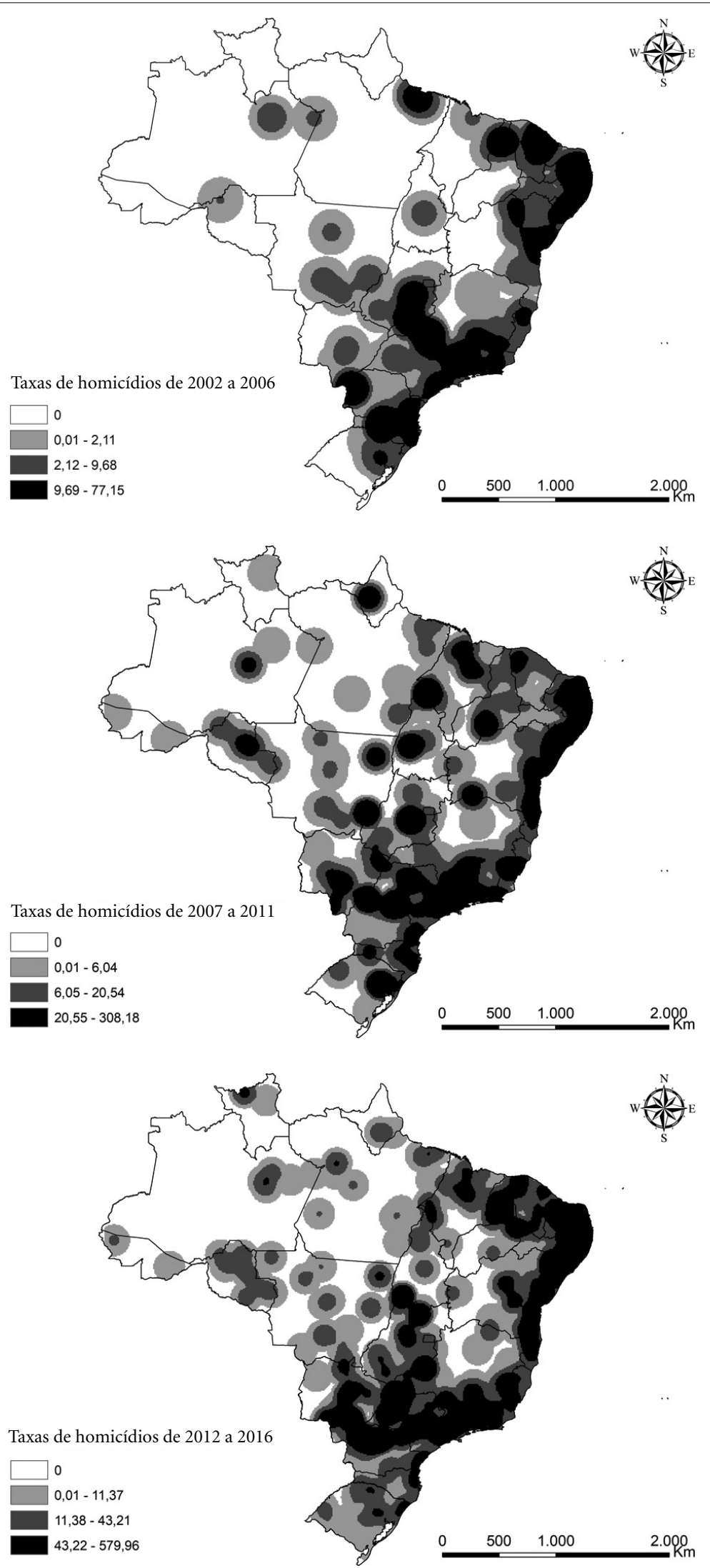

Figura 3. Mapas de Kernel das taxas de homicídios brasileiras de 2002 a 2016. 
O crescimento do número de homicídios contra LGBT no país aumentou, partindo de 158 casos no período de 2002 a 2006 para 558 casos no período de 2012 a 2016, o que representa um crescimento de $253 \%$. O número de homicídios no país de 2002 a 2006 foi 245.835 casos e aumentou para 292.103 casos no período de 2012 a 2016 , um crescimento de $18,82 \%$, ou seja, o número de homicídios de LGBT cresceu 13 vezes mais se comparado aos casos da população geral no mesmo período ${ }^{53}$.É importante destacar que não há uma sazonalidade nos homicídios de LGBT, ocorrendo variações por mês, ano, regiões e cidades, o que caracteriza uma falta de padrão dominante ao longo dos anos ${ }^{12,14}$.

Os jovens são os mais atingidos por esse tipo de crime devido a sua vulnerabilidade ${ }^{9,50,54}$. Os movimentos LGBT brasileiros há décadas reivindicam a criminalização da homofobia ou "LGBTfobia"11, porém apenas recentemente o Supremo Tribunal Federal (STF) equiparou a homofobia ao crime de racismo ${ }^{55}$. Devido à sua complexidade só está ação não resolverá esse problema de saúde pública, mas constitui um passo importante no sentido de dar visibilidade à questão da homofobia.
Acredita-se que o estudo alcançou seu objetivo, mesmo recorrendo a fontes não oficiais na coleta de dados. Ele trouxe à tona informações relevantes e inéditas, sendo o primeiro no mundo com tantos detalhes sobre a temática, proporcionando visibilidade a um crime tão corriqueiro no país. Convém ressaltar que os dados de homicídios de LGBT foram registrados e cedidos pelo GGB, contudo todos os homicídios registrados foram revisados e corrigidos, quando necessário.

É importante destacar os homicídios de LGBT, independentemente de haver homofobia, é um problema de saúde pública e de violação sistemática dos direitos humanos. A finalidade do estudo foi a de apresentar à sociedade as características quantitativas dos crimes, suas vítimas e autores ocorridos no Brasil. Sugere-se que sejam feitos outros estudos para crimes não letais e suicídios de LGBT. No tocante aos transgêneros tem-se a necessidade de estudos específicos por ser um grupo mais "marginalizado" e esquecido pelo poder público e sociedade. O crescimento de estudos acerca da temática contribuirá no enfrentamento da homofobia, trazendo outros pontos de vistas e novas informações, algo necessário num país que a cada ano há aumento da violência e de discurso de ódio contra esta população.

\section{Colaboradores}

WG Mendes: Coleta de dados, tabulação, análise descritiva e espacial. Redação do texto e padronização das normas de acordo com a revista. CMFP Silva: Revisão do texto e sugestão de partes significativas 


\section{Agradecimentos}

Ao presidente do GGB, o sr. Marcelo Cerqueira, por ter cedido os dados de homicídios contra LGBT. Ao presidente de honra do GGB, o prof. Dr. Luiz Mott, por ter dado contribuições importantes ao texto. Ao pesquisador do GGB e proprietário do blog Homofobia Mata, o sr. Eduardo Michels por ter cedido e me ajudado na revisão dos dados de homicídios. Ao Cientista Social Valdeci Doneda pela revisão e sugestões no texto.

Este artigo foi apoiado pelo Departamento de Epidemiologia e Métodos Quantitativos em Saúde, Escola Nacional de Saúde Pública Sergio Arouca, Fundação Oswaldo Cruz, Brasil.

À Fundação de Amparo à Pesquisa do Estado do Amazonas (FAPEAM) pela bolsa de doutorado concedida ao primeiro autor.

\section{Referências}

1. Cerqueira D, Lima RS, Bueno S, Neme C, Ferreira H, Coelho D, Alves PP, Pinheiro M, Astolfi R, Marques D, Reis M, Merian F. Atlas da Violência 2018 [Internet]. Brasília: Instituto de Pesquisa Econômica Aplicada (IPEA); 2018 Sep [cited 2018 Sep 11]. Available from: http://www.ipea.gov.br/portal/images/stories/ PDFs/relatorio_institucional/180604_atlas_da_violencia_2018.pdf

2. Wanzinack C, Signorelli MC, Reis C. Homicides and socio-environmental determinants of health in Brazil: a systematic literature review. Cad Saude Publica [Internet]. 2018 Nov 29 [cited 2019 Mar 30]; 34(12). Available from: http://www. scielo.br/scie lo.php?script=sci_arttext $\&$ pid $=$ S0102-311X2018 001202001\&lng=en\&tlng=en

3. Reichenheim ME, Souza ER, Moraes CL, Jorge MHPM, Silva CMFP, Minayo MCS. Violence and injuries in Brazil: the effect, progress made, and challenges ahead. Lancet 2011; 377(9781):1962-1975.

4. Rivara FP, Studdert DM, Wintemute GJ. Firearm-Related Mortality: A Global Public Health Problem. JAMA 2018; 320(8):764.

5. Luckenbill DF. Criminal Homicide as a Situated Transaction. Soc Probl 1977; 25(2):176-186.

6. Murray J, Cerqueira DRC, Kahn T. Crime and violence in Brazil: Systematic review of time trends, prevalence rates and risk factors. Aggress Violent Behav 2013; 18(5):471-483.

7. Sharkey P, Friedson M. The Impact of the Homicide Decline on Life Expectancy of African American Males. Demography [Internet]. 2019 Mar 5 [cited 2019 Mar 30]; Available from: http://link.springer. com/10.1007/s13524-019-00768-4

8. World Health Organization (WHO). World Health Statistics 2018: Monitoring health for the SDGs [Internet]. S.1.: WHO; 2018 [cited 2018 Nov 9]. Available from: https://www.who.int/gho/publications/world_ health_statistics/2018/en/

9. Cerqueira D, Lima RS, Bueno S, Neme C, Ferreira H, Coelho D, Alves PP, Pinheiro M, Astolfi R, Marques D, Reis M, Merian F. Atlas da Violência 2019 [Internet]. Brasília: Instituto de Pesquisa Econômica Aplicada (IPEA); 2019 Jul [cited 2019 Jul 27]. Available from: http://www.ipea.gov.br/portal/images/stories/ PDFs/relatorio_institucional/180604_atlas_da_violencia_2018.pdf

10. Transgender Europe (TGEU). TMM Update Trans Day of Remembrance 2018 [Internet]. Berlin, Germany: Transgender Europe (TGEU); 2018 Nov [cited 2019 Mar 30]. Available from: https://transrespect.org/en/ tmm-update-trans-day-of-remembrance-2018/

11. Mott L. Homo-afetividade e direitos humanos. Rev Estud Fem 2006; 14(2):509-521.

12. Mott L, Michels E. Relatório 2018: Assassinatos de LGBT no Brasil [Internet]. Brasil: Grupo Gay da Bahia - GGB; 2019 [cited 2017 May 1]. Available from: https://homofobiamata.files.wordpress.com/2017/01/ relatc3b3rio-2016-ps.pdf

13. Mott L, Cerqueira M. Causa Mortis: Homofobia. Salvador: Grupo Gay da Bahia; 2001.

14. Mott L, Cerqueira M, Almeida C. O Crime Anti-homossexual no Brasil. Salvador: Grupo Gay da Bahia; 2002. 
15. International Lesbian, Gay, Bisexual, Trans and Intersex Association (ILGA). LGBulleTIn \#74 - The week in LGBTI news [Internet]. 2019 [cited 2019 Mar 30]. Available from: https://ilga.org/lgbti-news-74-ilga-jan -2017

16. Organização das Nações Unidas do Brasil (ONU Brasil). PNUD e parceiros lançam campanha para combater homofobia e violência de gênero [Internet]. ONU Brasil. 2019 [cited 2019 Mar 30]. Available from: https://nacoesunidas.org/pnud-e-parceiros-lancam-campanha-para-combater-homofobia-e-violencia-de-genero/

17. Brasil. Ministério dos Direitos Humanos (MDH). Brasil registra uma morte por homofobia a cada 16 horas, aponta relatório [Internet]. 2019 [cited 2019 May 10]. Available from: https://noticias.uol.com.br/ cotidiano/ultimas-noticias/2019/02/20/brasil-matou-8-mil-lgbt-desde-1963-governo-dificulta-divulgacao-de-dados.htm

18. Mercado Mondragon J. Intolerance toward Sexuality Diversity and Homophobic Crimes. A Sociological Analysis. Sociologica 2009; 24(69):123-156.

19. Ministério da Mulher, da Família e dos Direitos Humanos (MMFDH). Disque 100, Disque Direitos Humanos - Relatório 2019 [Internet]. Brasília: MMFDH; 2019. [cited 2019 May 10]. Available from: https:// www.mdh.gov.br/informacao-ao-cidadao/ouvidoria/ balanco-disque-100

20. Sagar AD, Najam A. The human development index: a critical review. Ecol Econ 1998; 25(3):249-264.

21. Brasil de Fato. $10 \%$ dos brasileiros são LGBTI, mas estão sub-representados na política [Internet]. 2017 [cited $2018 \mathrm{Feb} 7]$. Available from: https://www. brasildefato.com.br/2017/06/19/cerca-de-10-da-populacao-brasileira-pessoas-lgbti-sao-sub-representadas-na-politica/index.html

22. Mundo Mais. Censo gay [Internet]. 2011 [cited 2018 Feb 7]. Available from: http://web.archive.org/ web/20110706153632/http://www.mundomais.com. br/exibemateria2.php?idmateria $=334$

23. Scrivano R, Neto JS. Potencial de compras LGBT é estimado em $R \$ 419$ bilhões no Brasil. O Globo [Internet]. 2018 Oct 31; [cited 2018 Oct 31]. Available from: https://oglobo.globo.com/economia/potencialde-compras-lgbt-estimado-em-419-bilhoes-no-brasil-15785227

24. Gates GJ. Same-sex Couples and the Gay, Lesbian,Bisexual Population: New Estimates fromthe American Community Survey [Internet]. Los Angeles, USA Universidade da Califórnia; 2019 [cited 2019 Aug 12]. Available from: http://www.lgbtdata.com/uploads/1/0/8/8/10884149/samesexcouplesandglbpopacs.pdf

25. Bakke F, Graaf H de, Haas S de, Kedde H, Kruijer H, Wijsen C. Rapport Seksuele gezondheid in Nederland 2009 [Internet]. Utrecht: Rutgers Nisso Groep; 2019 [cited 2019 Aug 12]. Available from: https://fiom.nl/ sites/default/files/files/RNG_rapport-seksuele-gezondheid-in-nederland-2009.pdf

26. Dahlgreen W, Shakespeare A-E. https://yougov. co.uk/topics/lifestyle/articles-reports/2015/08/16/ half-young-not-heterosexual [Internet]. London: YouGov; 2015 [cited 2019 Aug 12]. Available from: https://yougov.co.uk/topics/lifestyle/articles-reports/2015/08/16/half-young-not-heterosexual
27. ISTAT. Discriminazioni in base al genere, all'orientamento sessuale e all'appartenenza etnica [Internet]. Roma: Istituto Nazionale di Statistica; 2011 [cited 2019 Aug 12]. Available from: http://www.istat.it/it/ archivio/30726

28. Cliff AD, Ord JK, Cliff AD. Spatial processes: models \& applications. London: Pion; 1981.

29. Altman DG, Bland JM. Statistics Notes: Quartiles, quintiles, centiles, and other quantiles. BMJ 1994; 309(6960): 996-996.

30. Moran PP. Notes on continuous stochastic phenomena. Biometrika 1950; 37(1-2):17-23.

31. Chou YH. Map Resolution and Spatial Autocorrelation. Geogr Anal 2010; 23(3):228-246.

32. Bivand R. spdep: Spatial dependence: weighting schemes, statistics and models ( $\{R\}$ package version 0.5 37) [Internet]. 2011. [cited 2019 Aug 12]. Available from: http://CRAN.R-project.org/package $=$ spdep

33. Tiefelsdorf M, Griffith DA, Boots B. A Variance-Stabilizing Coding Scheme for Spatial Link Matrices. Environ Plan A 1999; 31(1):165-180.

34. Bailey TC, Gatrell AC. Interactive spatial data analysis. Harlow Essex, New York: Longman Scientific \& Technical, J. Wiley; 1995.

35. Programa das Nações Unidas para o Desenvolvimento (PNUD), Instituto de Pesquisa Econômica Aplicada (IPEA). O Índice de Desenvolvimento Humano Municipal Brasileiro: série atlas do desenvolvimento humano no Brasil 2013 [Internet]. Brasília: PNUD, IPEA; 2019 [cited 2019 Apr 1]. Available from: http:// ipea.gov.br/portal/images/stories/PDFs/130729_AtlasPNUD_2013.pdf

36. Tomsen S. Victims, Perpetrators and Fatal Scenarios: A Research Note on Anti-Homosexual Male Homicides. Int Rev Vict 2002; 9(3):253-271.

37. Mouzos J, Thompson S. Gay-Hate Related Homicides: An Overview of Major Findings in New South Wales [Internet]. 2000. [cited 2019 Apr 1]. Available from: http://search.proquest.com/docview/9862650?accountid $=26662$

38. Boivin RR. Características y factores de la violencia homicida contra las minorías sexuales en la Ciudad de México, 1995-2013. Sex Salud Soc 2016; (23):22-57.

39. Oliveira JMD. Desejo, preconceito e morte: assassinatos de LGBT em Sergipe - 1980 a 2010. Natal: Universidade Federal do Rio Grande do Norte; 2012.

40. Bartlett P. Killing gay men, 1976-2001. Br J Criminol 2007; 47(4):573-595.

41. Stacey M. Distinctive Characteristics of Sexual Orientation Bias Crimes. J Interpers Violence 2011; 26(15): 3013-3032.

42. Prunas A, Clerici CA, Gentile G, Muccino E, Veneroni L, Zoja R. Transphobic Murders in Italy: An Overview of Homicides in Milan (Italy) in the Past Two Decades (1993-2012). J Interpers Violence 2015; 30(16):28722885.

43. Gruenewald J, Kelley K. Exploring Anti-LGBT Homicide by Mode of Victim Selection. Crim Justice Behav 2014; 41(9):1130-1152. 
44. Kelley KK. A Mixed-Method Examination of Homicides Targeting LGBT Individuals in the United States. 2013 [cited 2017 Jan 23]. Available from: http://scholarworks.uark.edu/etd/771/?utm_source=scholarworks.uark.edu\%2Fetd\%2F771\&utm_medium=PDF\&utm_campaign=PDFCoverPages

45. Carrara S, Vianna ARB. “Tá lá o corpo estendido no chão... ": a violência letal contra travestis no município do Rio de Janeiro. Physis Rio J 2006;16(2):233-249.

46. Granados JA, Delgado G. Mortality by homicide in homosexuals: characterization of the cases registered in Mexico between 1995 and 2000. Am J Forensic Med Pathol 2008; 29(1):43-48.

47. Gruenewald J. Are Anti-LGBT Homicides in the United States Unique. J Interpers Violence 2012; 27(18): 3601-3623.

48. Waters E, Jindasurat C, Wolfe C. A report from the $\mathrm{Na}$ tional Coalition of Anti-Violence Programs: Lesbian, gay, bisexual, transgender, queer, and hiv-affected hate violence in 2015 - 2016 release edition [Internet]. New York: Arcus Foundation; 2016 [cited 2016 Sep 11]. Available from: http://www.avp.org/storage/documen ts/ncavp_hvreport_2015_final.pdf

49. Andrade LT, Diniz AMA. A reorganização espacial dos homicídios no Brasil e a tese da interiorização. Rev Bras Estud Popul 2013; 30(Supl.):S171-191.

50. Frota MTE. Determinantes dos Homicídios no Brasil. Fortaleza: Universidade Federal do Ceará; 2014.

51. Consejo Ciudadano para la Seguridad Pública y la Justicia Penal A.C. Las 50 ciudades más violentas del mundo 2018 [Internet]. Ciudad de México, México: Consejo Ciudadano para la Seguridad Pública y la Justicia Penal A.C.; 2019 [cited 2019 May 1] p. 17. Available from: http://seguridadjusticiaypaz.org.mx/ files/estudio.pdf

52. Souza SR. Respostas brasileiras à violência urbana no campo da segurança pública: os movimentos sociais e as organizações não-governamentais [tese]. Rio de Janeiro: Fiocruz; 2008.

53. Brasil. Ministério da Saúde (MS). TabNet Win32 3.0: Óbitos por Causas Externas - Brasil [Internet]. 2019 [cited 2019 May 27]. Available from: http://tabnet. datasus.gov.br/cgi/deftohtm.exe?sim/cnv/ext10br.def

54. Pereira FNA, Queiroz BL. Diferenciais de mortalidade jovem no Brasil: a importância dos fatores socioeconômicos dos domicílios e das condições de vida nos municípios e estados brasileiros. Cad Saude Publica [Internet]. 2016 [cited 2019 Apr 28];32(9). Available from: http://www.scielo.br/scielo.php?script=sci_arttext\&pid=S0102-311X2016000905012\&lng $=p t \& t \operatorname{lng}=p t$

55. El País. Maioria do STF decide que homofobia é crime [Internet]. 2019 [cited 2019 May 27]. Available from: https://brasil.elpais.com/brasil/2019/05/23/politica/1558635166_112275.html

Artigo apresentado em 30/05/2019

Aprovado em 07/08/2019

Versão final apresentada em 18/11/2019 